estão mais - tão - dispostos ao prazer do olhar masculino, olhar este tão criticado por Mulvey. Há uma recusa à passividade das protagonistas, ao domínio de seus corpos, à opressão da sexualidade feminina, das relações de poder e da maternidade como potencial fragilizador. Em Estrada da fúria, Max perde o carro, a liberdade, as botas e o protagonismo, não é um filme sobre ele, é um filme sobre Furiosa. É um filme sobre a violência contra as mulheres e como os homens podem colaborar nessa luta sem roubar-lhes o espaço.

Mulvey questiona o papel da mulher na ordem simbólica do cinema clássico e como ela é inserida na cultura patriarcal como "o outro" “(...), posicionada numa ordem simbólica na qual o homem pode viver suas fantasias e obsessões através do comando linguístico, impondo-o à imagem silenciosa da mulher que permanece fixa em seu lugar de sustentáculo, mas não de produtora de significado", afirma a novelista australiana. Entretanto, a representação feminina edificada no cinema clássico através desse olhar em função do falo já não se sustenta mais, já não é mais tolerada, por mais que ainda seja dominante. $\mathrm{O}$ silêncio foi quebrado pelas feministas e por uma geração inteira de mulheres que não se sentem representadas pela imagem de si que veem na tela, Mad Max: estrada da fúria torna-se, dessa forma, mais que um filme histórico, um filme necessário.

Andressa Gordya

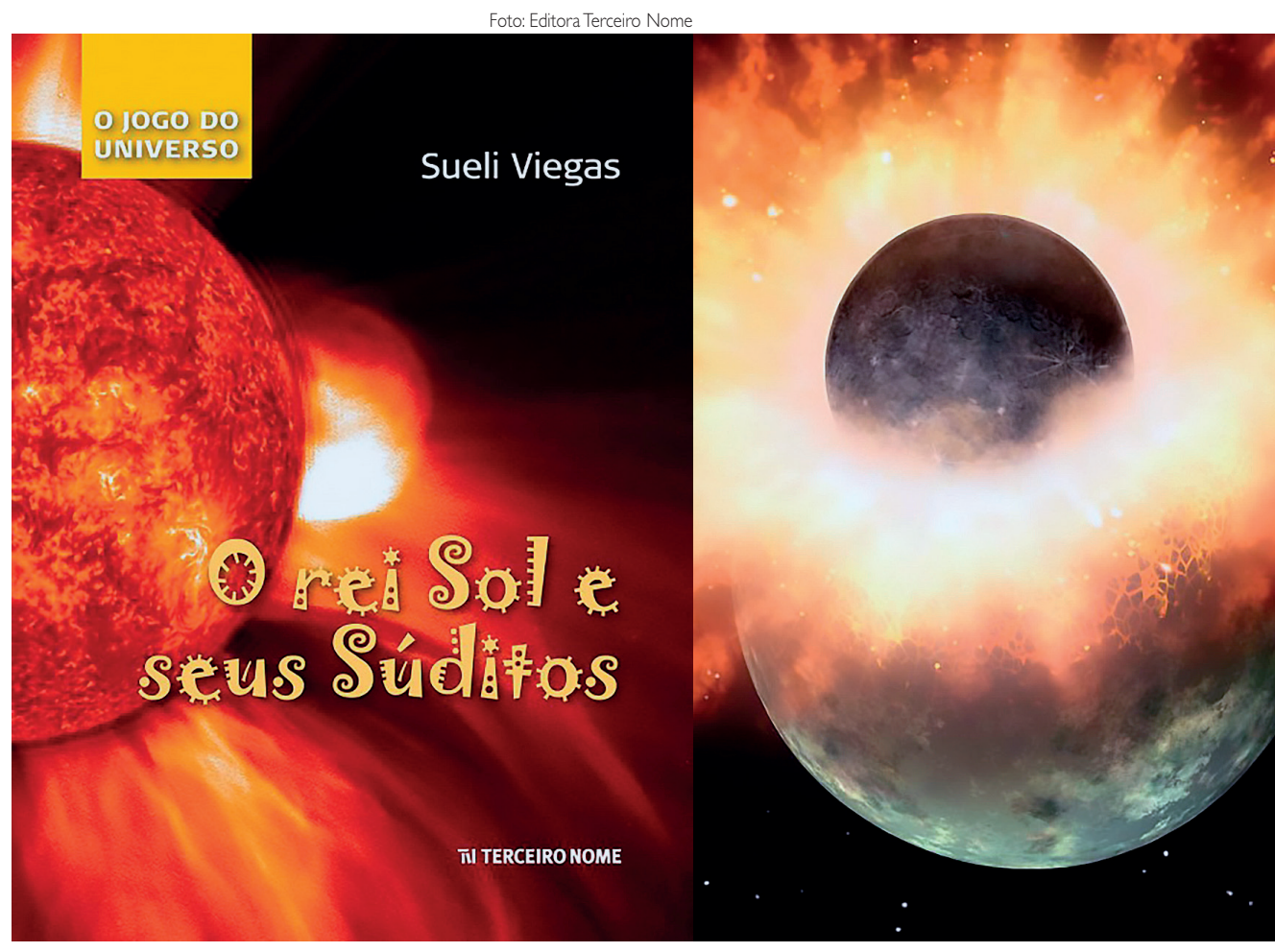

DIVULGAÇÃO CIENTÍFICA

\title{
MAIS PERTO DO CÉU: COLEÇÃo DE LIVROS APROXIMA ASTRONOMIA DA ESCOLA
}

O céu e as estrelas sempre fizeram parte do cotidiano da humanidade seja por motivos religiosos, seja por questôes práticas como contar o tempo ou para saber sua localização. Foi pelo desejo de entender o movimento dos objetos celestes e, mais tarde, a origem do universo que nasceu a astronomia, considerada a mais antiga das ciências naturais. Porém, se o céu está ao alcance de todos, a astronomia permanece distante dos bancos escolares. "É uma pena porque ela pode ser uma ótima ferramenta para ensinar os conceitos de física, por exemplo", afirma a astrônoma Sueli Viegas, professora titular do Departamento de Astronomia, Geofísica e Ciências Atmosféricas (IAG), da Universidade de São Paulo (USP), que deverá lançar este semestre um livro de divulgação da astronomia para professores.

Viegas credita a ausência da astronomia no ensino a dois problemas: o currículo das escolas e a formação dos 

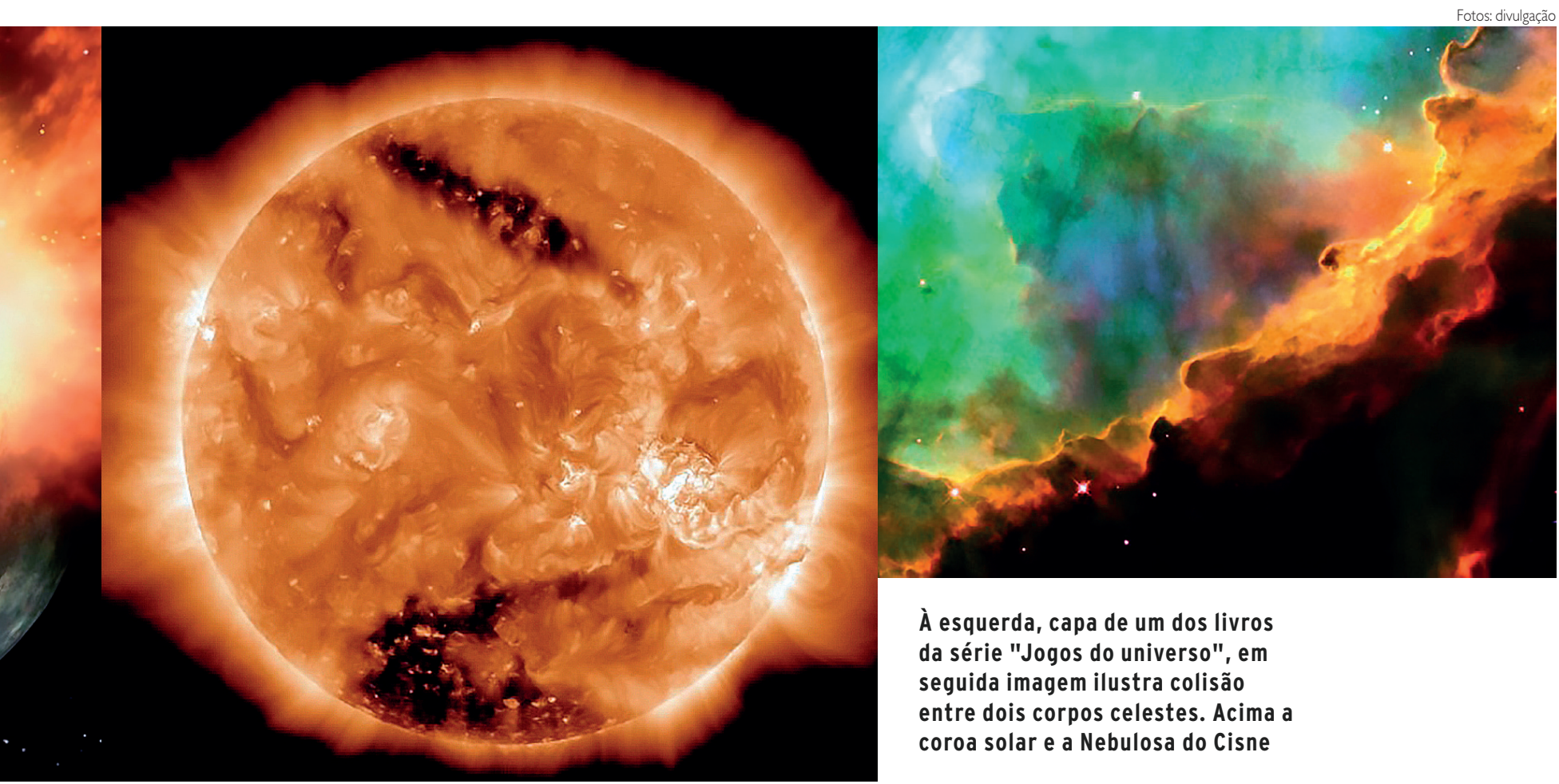

À esquerda, capa de um dos livros da série "Jogos do universo", em seguida imagem ilustra colisão entre dois corpos celestes. Acima a coroa solar e a Nebulosa do Cisne

professores. "Basicamente, os alunos estudam o movimento da Terra ao redor do sol, da lua ao redor da Terra, um conteúdo que é parte do que chamamos de astronomia fundamental. A questão é que quando olhamos para o céu, vemos estrelas que se movem e que se modificam. Nosso olhar alcança muito mais", diz ela. "Infelizmente, no entanto, as escolas não estão preparadas para oferecer esse conhecimento", afirma.

HISTÓRIA DO UNIVERSO Longe das salas de aula, Sueli Viegas dedica-se à divulgação da astronomia especialmente para o público jovem e leigo. "Eu quis escrever um texto informativo e leve, que contasse a história da origem do universo com linguagem simples", descreve. Para representar conceitos bastante abstratos, ela adotou o uso de metáforas, ilustra- ções e fotografias. "Também optei por ter um protagonista, a figura do próton, uma partícula inicial, que conta sua própria história”. A narrativa foi dividida em quatro partes: o início do universo até a formação das primeiras partículas; a formação das galáxias; a Via Láctea e, finalmente, no último livro o assunto é o sistema solar. O objetivo foi criar um material que pudesse ser facilmente utilizado por professores e que fosse visualmente interessante para os alunos.

Além de aproximar a academia de alunos e professores, um dos objetivos da pesquisadora é estimular mais meninas a estudar astronomia. "Meu pai era médico em Botucatu, interior de São Paulo, em uma época em que as meninas iam para colégios de freira, mas eu fui estudar com os meninos em uma escola pública, porque ele dizia que eram as melhores. Isso me marcou profundamente. Nunca pensei que ser mulher fizesse diferença. Fiz tudo o que homens fizeram e às vezes isso, de fato, incomodava", conta. Sueli Viegas afirma que, ao longo de sua carreira, encontrou poucas mulheres. "Há dados que mostram que apenas 30\% dos astrônomos são mulheres. Em cargos de comando ainda é bastante raro", enfatiza. Juntamente com dois colegas do IAG, ela finaliza um livro com atividades para ensino de física por meio da astronomia, com previsão de lançamento ainda no primeiro semestre deste ano. A astrônoma da USP espera que os livros possam contribuir para a capacitação dos professores em astrofísica. 